Journal of Advanced Research in Fluid Mechanics and Thermal Sciences

Journal homepage: www.akademiabaru.com/arfmts.html ISSN: 2289-7879

\title{
The Effect of Sedimentation to The Pump Sump System by Using Computational Fluid Dynamics (CFD) Model
}

\author{
Norsyazliana Syamira Saiful Anuar ${ }^{1}$, Siti Hidayah Abu Talib ${ }^{1,}{ }^{*}$, Nur Fatin Izureen Radzaly ${ }^{1}$, Syarifah \\ Intan Najla Syed Hashim ${ }^{1}$, Muhammad Salleh Abustan ${ }^{1}$
}

1 Faculty of Civil and Environmental Engineering, Universiti Tun Hussein Onn Malaysia, 86400 Parit Raja, Batu Pahat, Johor, Malaysia

\section{ARTICLE INFO ABSTRACT}

\section{Article history:}

Received 18 December 2019

Received in revised form 25 January 2020

Accepted 25 January 2020

Available online 25 March 2020

Keywords:

Sedimentation; pump sump; CFD

\begin{abstract}
Sedimentation is the one of the major problems in the operational of pump sump system. Therefore, study is conducted to determine the efficiency of pump sump due to sedimentation using ANSYS Fluent. Model simulation is conducted using different size of sediment and different water flow velocity to observed how it will effect on pump sump. The CFD model are well computed the sediment deposition in pump sump. Percentage of particle accumulate increased with increased of particle size but at lower velocity. While for sediment deposition area, most of the particle will be deposited at the inlet of the pump sump especially for larger particle.
\end{abstract}

Copyright $\odot 2020$ PENERBIT AKADEMIA BARU - All rights reserved

\section{Introduction}

Pump sump intake plays an important role in the water supply. There are many usages of the pump. For example, in water resources, the pump is used to transfer raw water (from rivers, lakes, etc.) to the intake. The pump is selected based on system requirements, discharge pressure required, flow capacity required and availability of space [1]. Nowadays, there are much development has been implemented resulting in many new land clearings. Some of the development has been carried out near the river and this kind of development will produce sediment loads in the river which will transport to the reservoir. Besides, most sediment releases come from land development activities where it may cause sedimentation problems in a watercourse.

Sedimentation is the build-up (aggradation) of sediment on the land surface or the bed of a watercourse and causes particles to depart from flow lines [2-3]. Therefore, it allowing particles in water to settle out of the suspension under the effect of gravity. Sedimentation will give an effect to the pump sump system especially to its efficiency. The smaller particle or the suspended particle will flow to the intake and this may cause erosion and abrasion to the expensive hydraulic machinery [4]. Besides, excessive sedimentation in the waterway will cause sediment entrainment and reduction of

\footnotetext{
* Corresponding author.

E-mail address: hidayaht@uthm.edu.my (Siti Hidayah Abu Talib)
} 
pump efficiency in delivering because of clogged or locked at the outlet of the structure and it may lead to damage to the system because of the pump system is not designed for sediment passage. [56]. Furthermore, sedimentation problems can lead to pump operational difficulties due to it being either conveyed with the diverted flow or deposited in the intake and interferes with the flow [7]. Besides, sedimentation will reduce the water storage and eliminate the capacity of water flow regulation which will cause economic losses due to maintenance work and operational lack.

A physical model is commonly used to investigate the effect of sedimentation on the pump sump system. However, usage of the physical model will require high cost due to construction and transportation of the physical model itself besides it also required a long period.

Computational fluid dynamics (CFD) is one of the tools that can be used to investigate the problem which it is can save cost and time. However, it requires skill and quite difficult to understand how to use the software which needs a lot of studies. CFD has now become one of an important tool to study the flow of either the flow of gas, solid or liquid and it also can analyze single-phase and multiphase flow [8]. Since CFD has been chosen as a method to analyze the problem. Therefore, more research has to be done to decide the most appropriate CFD model that suitable to use where other similar research works are studied to understand the different model and theories are used in CFD as following.

Wingstedt and Reif [9] conducted a numerical simulation of particle dispersion in an urban area using the Euler-Lagrange model. The realizable $k-\varepsilon$ model was used for turbulence modeling and the discrete phase model (DPM) was used for the particle transport model. The results obtained show that ANSYS Fluent is capable to predict the dispersion and deposition of the particle.

Kaushal et al., [10] have used multiphase flow ANSYS Fluent modeling to study about CFD modeling for pipeline flow of fine particles at high concentration. Two types of models are used such as mixture model and Eulerian model to modeled three-dimensional concentration distributions, pressure drops, and velocity distributions. The mixture model fails to predict pressure drops correctly. The Eulerian model gives fairly accurate predictions for pressure drop at all the efflux concentrations and flows velocities.

Yan [11] conducted a CFD model to investigate the 3D modeling of hydrodynamics, sediment transport, settling and resuspension under unsteady conditions in an urban stormwater detention basin. Discrete phase model (DPM) is been used to observed sediment transport. RNG k- $\varepsilon$ model is used to represent the turbulent phenomenon. For the results, the simulated flow pattern showed a good level of agreement with the measured spatial distribution of particle size.

Gopaliya and Kaushal [12] have conducted modeling of sand-water slurry flow through the horizontal pipe using CFD using the Eulerian model. The turbulence model that has been used is the RNG k- $\varepsilon$ model. As a result, the local volumetric concentration of solid-phase across pipe outlet is very well simulated for all three particle sizes under consideration. However, scatter in data of various flow parameters especially in the case of slurry flows with bigger particle sizes indicates that the model used in the present study needs further development.

Tarpagkou and Pantokratoras [13] have conducted CFD methodology to investigate the 3D hydrodynamics and flow behavior of a sedimentation tank using discrete phase model. RNG k- $\varepsilon$ model is used for the turbulence model.

The next study has been done by Bikmukhametov [14] which to study the capabilities of CFD software ANSYS Fluent in the modeling of particle flows. The Eulerian granular model has been used to simulate particle plug propagation in bent pipes and the DPM model was used to determine the critical velocity. The realizable $k-\varepsilon$ model is used for turbulence modeling. As a result, the Eulerian granular model is capable to reproduce the particle plug movement in pipes and the results fit the 
experimental results. While for the DPM, it gives a reasonably good performance in predicting critical velocity in slurry flows, but the value of the velocity is underestimated.

Dufresne et al., [15] studied the use of CFD and particle tracking in other and various hydraulic conditions. $k-\varepsilon$ model is used for the turbulence model and DPM is used for particle tracking. As a result, CFD shows seems a good way to model sediment transport in the pilot tank.

Mohsin and Kaushal [16] used the Volume of Fluid (VOF) model to validate the invert trap efficiency for sewer solid management. VOF model is used because it is suitable for free surface flow and it coupled with the DPM model which is used to determine the sediment trapped. Realizable k- $\varepsilon$ is used as a turbulence model. As a result, the CFD model closely fits the experiment data.

This study aims to determine the sediment deposition area and accumulation in pump sump. Most of the researchers are conducted the sediment transport in the pipeline. However, the most appropriate models will be chosen based on similar research about sediment transport or particle tracking in fluid flow.

\section{Methodology}

Parameters that used in the simulation has been identified first such as velocity, flow rate, particle diameter and particle density. The model has been made based on the real physical model and 3D modelling have been developed by using Solidworks 2017. There is two water level that has been used in this study which is a minimum water level and normal water level. Unstructured grids and the tetrahedral mesh were used. The mesh has 1.13 million and 2.5 million elements for minimum and normal water level respectively.

For boundary condition, no-slip boundary condition was applied at walls and pressure-outlet at the outlet. At the inlet, velocity-inlet with velocity of $0.007 \mathrm{~m} / \mathrm{s}, 0.037 \mathrm{~m} / \mathrm{s}$ and $0.071 \mathrm{~m} / \mathrm{s}$ was used for both water level. Initial studies show that the standard $k-\varepsilon$ and RNG k- $\varepsilon$ has good agreement for swirling and vortex flow application while the realizable $k-\varepsilon$ model performs better in the complex flow $[8,17,18]$. Therefore, the realizable $k-\varepsilon$ model is used for the turbulence model. After that, the DPM is activated and the particle is released at the inlet surface of the pump model. Three particle sizes are used which is $800 \mu \mathrm{m}, 425 \mu \mathrm{m}$ and $150 \mu \mathrm{m}$ with a density of $1450 \mathrm{~kg} / \mathrm{m}^{3}$.

\section{Results}

Simulation has been analysed by using two different water level which is normal water level and minimum water level. Furthermore, each of water level is divided into three cases where there is three value of inlet velocity which is $0.007 \mathrm{~m} / \mathrm{s}, 0.037 \mathrm{~m} / \mathrm{s}$ and $0.07 \mathrm{~m} / \mathrm{s}$. Three are different particle sizes were injected for each velocity which is $150 \mu \mathrm{m}, 425 \mu \mathrm{m}$ and $800 \mu \mathrm{m}$.

\subsection{Sediment Deposition Area for Minimum Water Level}

\subsubsection{Case 1 - Velocity $0.007 \mathrm{~m} / \mathrm{s}$ with difference particle sizes}

Most of the particles are deposited at Zone 1 for particle size $800 \mu \mathrm{m}$. For particle $425 \mu \mathrm{m}$, the deposition area still at the Zone 1 but there is some of the particles are deposited at Zone 2 . While for the particle size of $150 \mu \mathrm{m}$, the deposition area started scattered from Zone 1 to 3 . 


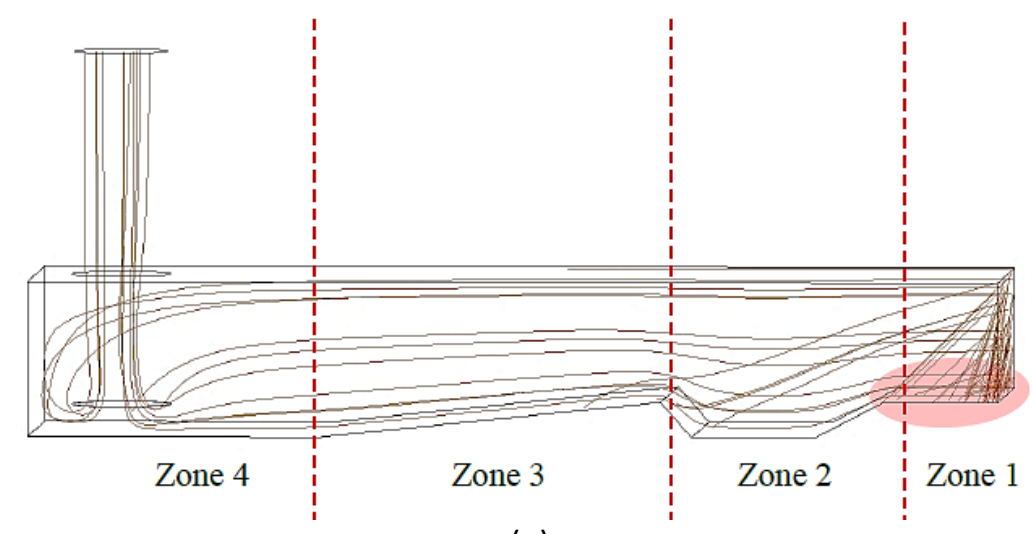

(a)

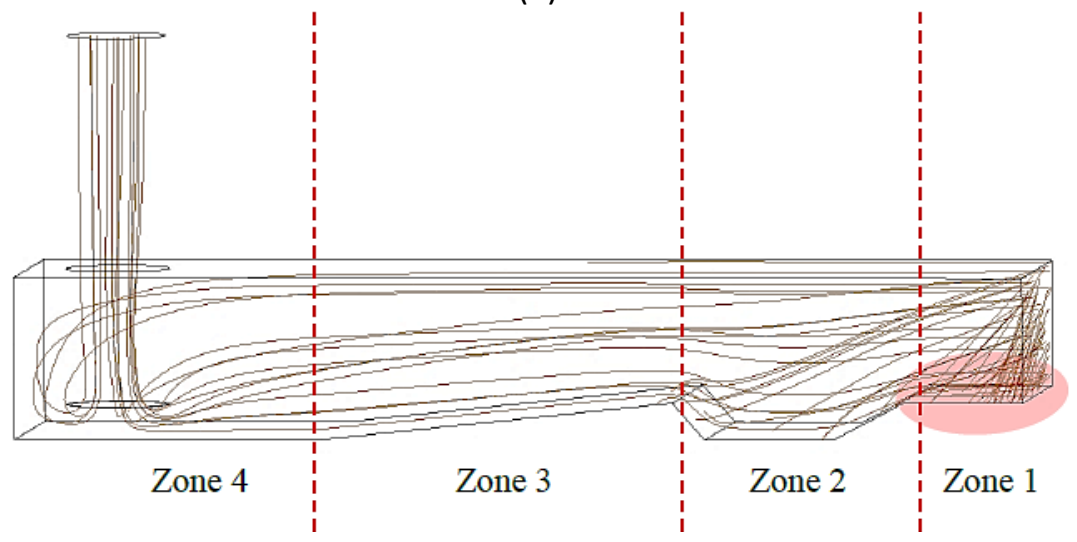

(b)

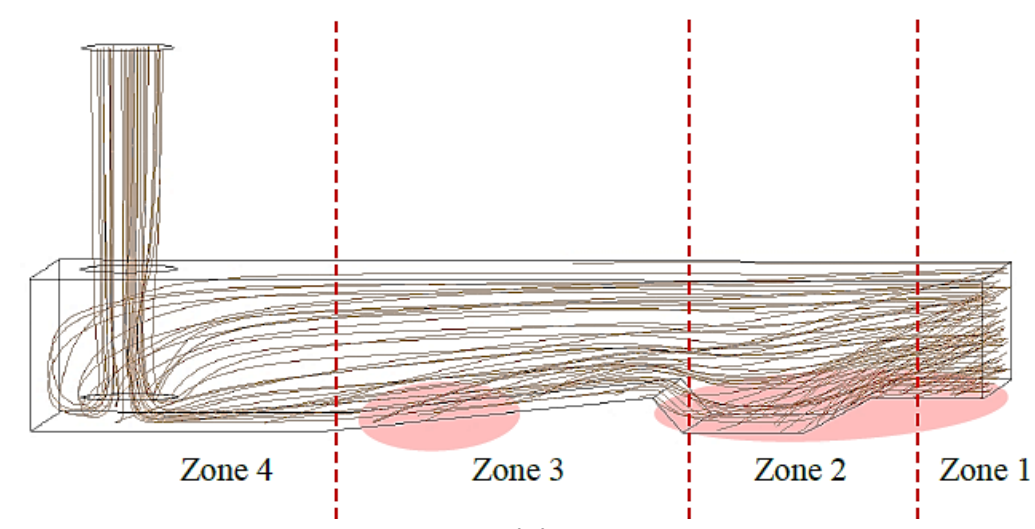

(c)

Fig. 1. (a) Velocity $0.007 \mathrm{~m} / \mathrm{s}$ with particle size $800 \mu \mathrm{m}$. (b) Velocity $0.007 \mathrm{~m} / \mathrm{s}$ with particle size $425 \mu \mathrm{m}$. (c) Velocity $0.007 \mathrm{~m} / \mathrm{s}$ with particle size $150 \mu \mathrm{m}$

\subsubsection{Case 2 - Velocity $0.037 \mathrm{~m} / \mathrm{s}$ with difference particle sizes}

Compared to Case 1, the deposition area for particle size $800 \mu \mathrm{m}$ more dispersed from Zone 1 to 2 and the particle that transported to the suction pipe are slightly increased. For particle size $425 \mu \mathrm{m}$, the deposition area of the particle same as $800 \mu \mathrm{m}$ but the particle transported for $425 \mu \mathrm{m}$ is more compared to $800 \mu \mathrm{m}$. Contrast to the particle size of $150 \mu \mathrm{m}$, most of the particle is transported into the suction pipe but there still have a few amounts of particle deposited at Zone 2, 3 and 4 . 


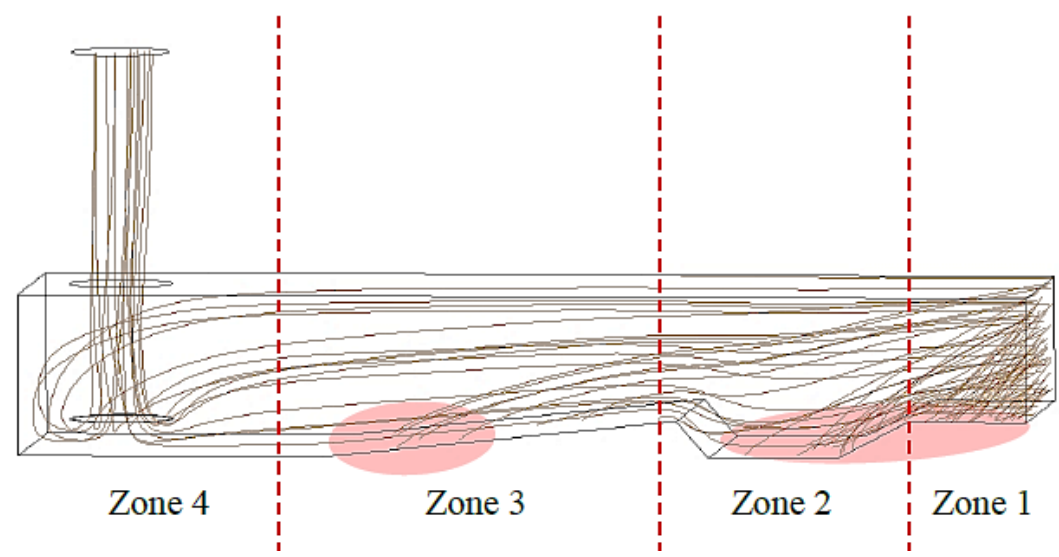

(a)

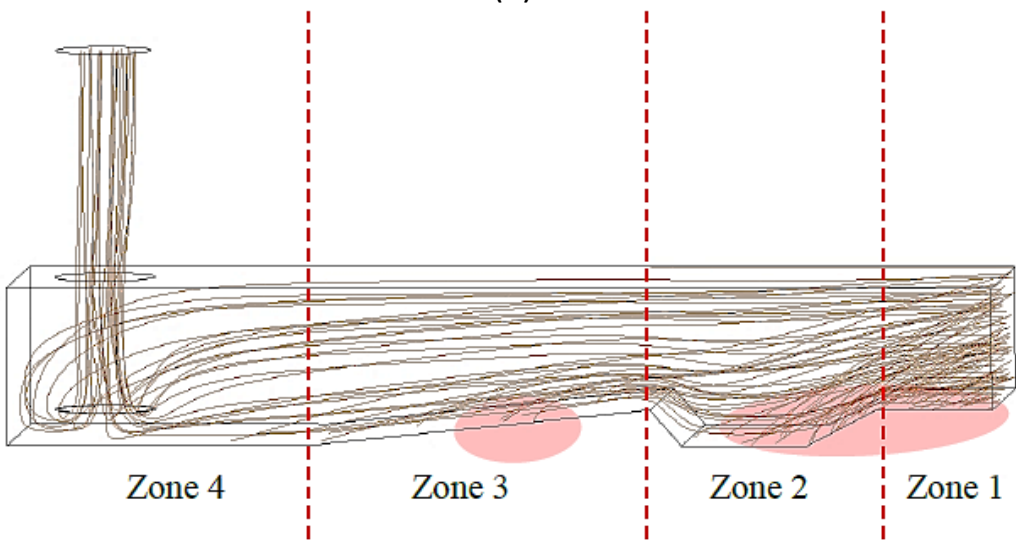

(b)

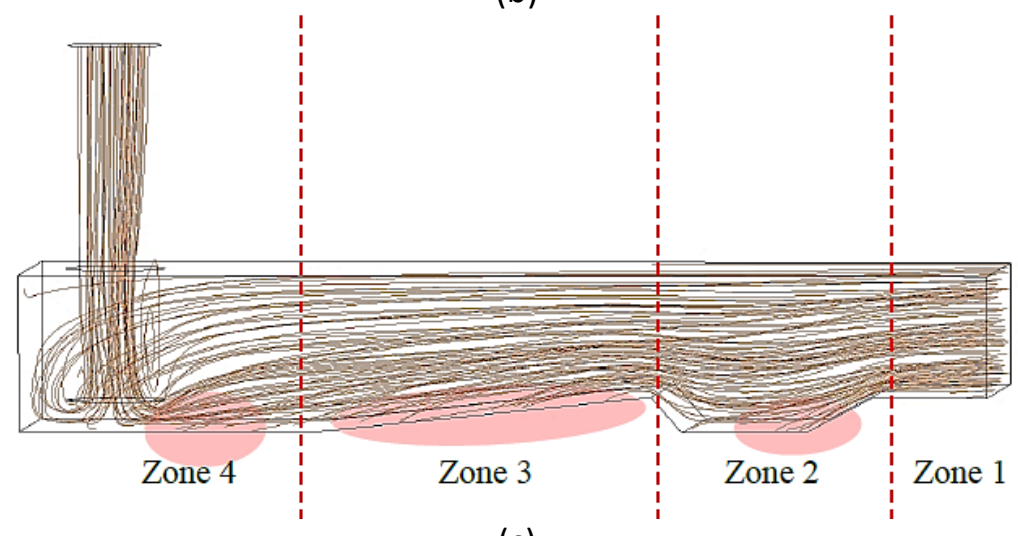

(c)

Fig. 2. (a) Velocity $0.037 \mathrm{~m} / \mathrm{s}$ with particle size $800 \mu \mathrm{m}$. (b) Velocity $0.037 \mathrm{~m} / \mathrm{s}$ with particle size $425 \mu \mathrm{m}$. (c) Velocity $0.037 \mathrm{~m} / \mathrm{s}$ with particle size $150 \mu \mathrm{m}$

\subsubsection{Case 3 - Velocity $0.071 \mathrm{~m} / \mathrm{s}$ with difference particle sizes}

The particle transported and deposition area for $800 \mu \mathrm{m}$ for this case are almost same as Case 2 but the particle is more dispersed compared to Case 2 . For particle size $425 \mu \mathrm{m}$, most of the particle deposited at Zone 2 and 3. Furthermore, the particle transported to the suction pipe is higher and there are only a few particles deposited at Zone 2 . 


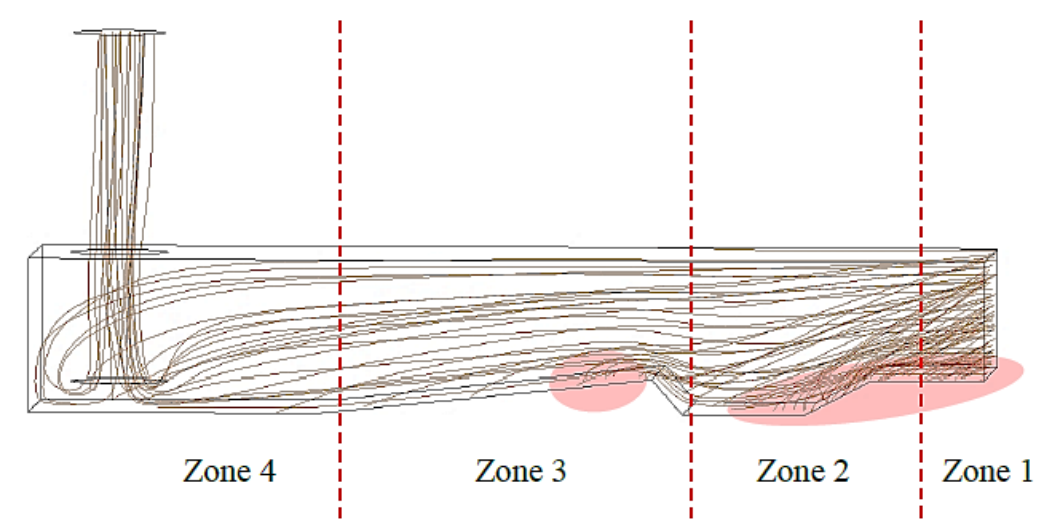

(a)

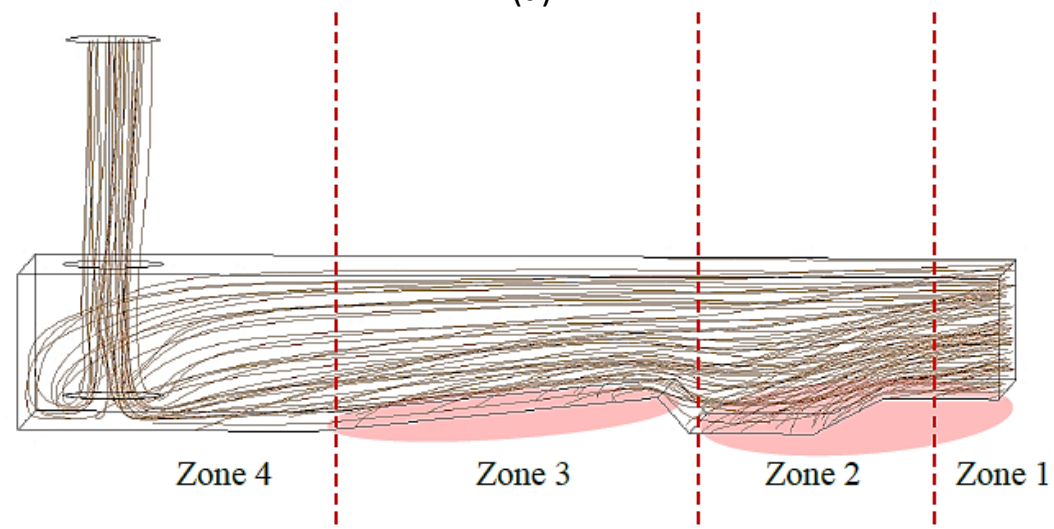

(b)

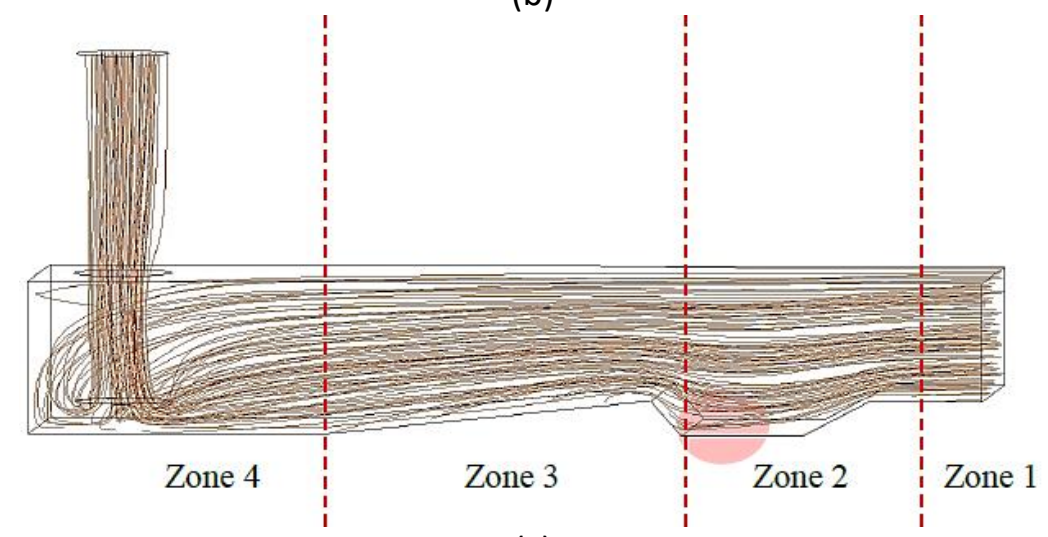

(c)

Fig. 3. (a) Velocity $0.071 \mathrm{~m} / \mathrm{s}$ with particle size $800 \mu \mathrm{m}$. (b) Velocity $0.071 \mathrm{~m} / \mathrm{s}$ with particle size $425 \mu \mathrm{m}$. (c) Velocity $0.071 \mathrm{~m} / \mathrm{s}$ with particle size $150 \mu \mathrm{m}$

\subsection{Sediment Deposition Area for Normal Water Level}

\subsubsection{Case 1 - Velocity $0.007 \mathrm{~m} / \mathrm{s}$ with difference particle sizes}

A particle with size $800 \mu \mathrm{m}$ shows that most of the particle deposited at Zone 1 and 2 . When smaller particle injected to the pump sump with size $425 \mu \mathrm{m}$, the particle start moves and deposited forward to Zone 3 and 4 . The particle transported into the suction pipe is increased. When particle sizes $150 \mu \mathrm{m}$ is injected, a particle that transported to the suction pipe is increased and the particle that deposited is reduced. There are some of the particle deposited at Zone 3 and 4. 


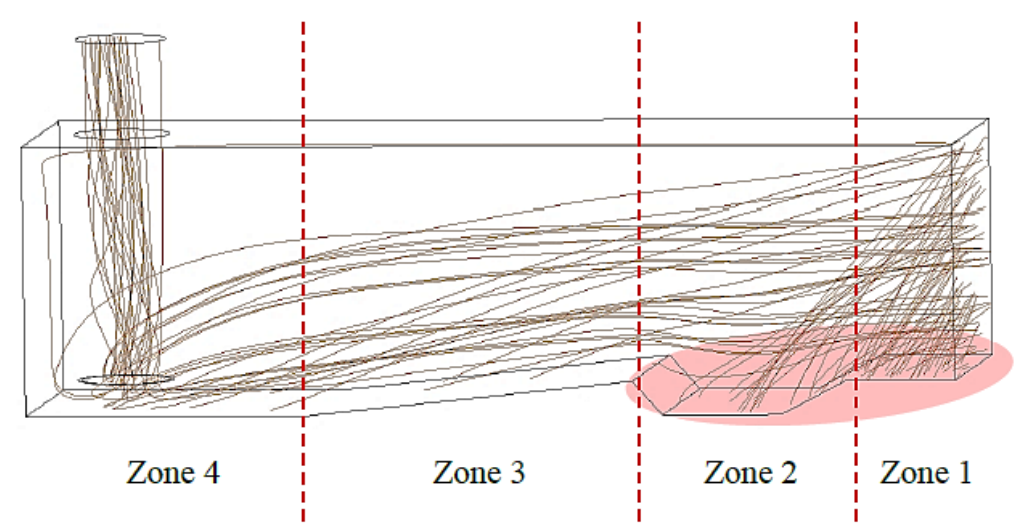

(a)

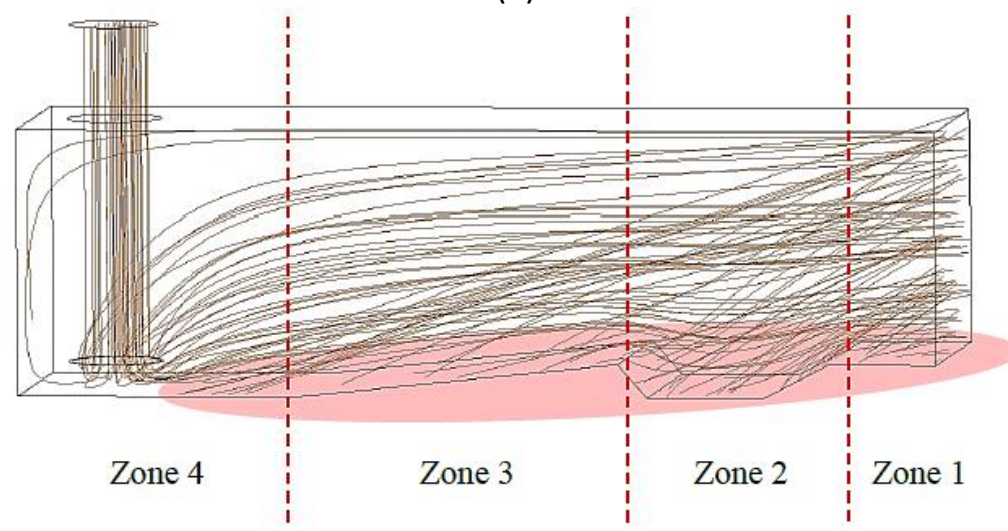

(b)

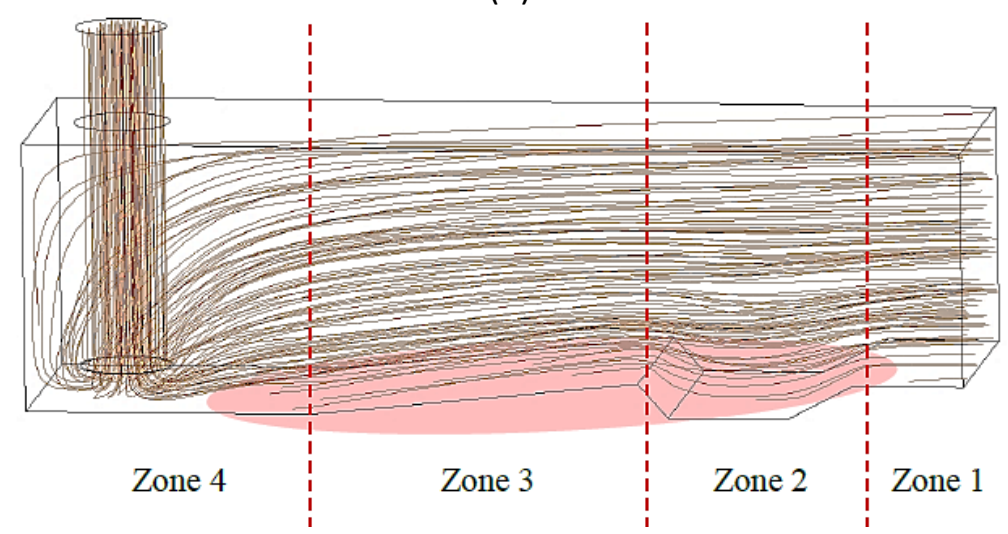

(c)

Fig. 4. (a) Velocity $0.007 \mathrm{~m} / \mathrm{s}$ with particle size $800 \mu \mathrm{m}$. (b) Velocity $0.007 \mathrm{~m} / \mathrm{s}$ with particle size $425 \mu \mathrm{m}$. (c) Velocity $0.007 \mathrm{~m} / \mathrm{s}$ with particle size $150 \mu \mathrm{m}$

\subsubsection{Case 2 - Velocity $0.037 \mathrm{~m} / \mathrm{s}$ with difference particle sizes}

In this case, the inlet velocity has been increased to $0.037 \mathrm{~m} / \mathrm{s}$. A particle with size $800 \mu \mathrm{m}$ shows that the particle is deposited more scattered from Zone 1 to 4 compared to Case 1 . When the particle size of $425 \mu \mathrm{m}$ is injected, most of the particle deposited at Zone 3 and 4 . For particle size $150 \mu \mathrm{m}$, there are only a few particles deposited along the Zone 1 to Zone 3 and most of the particle are transported into the suction pipe. 


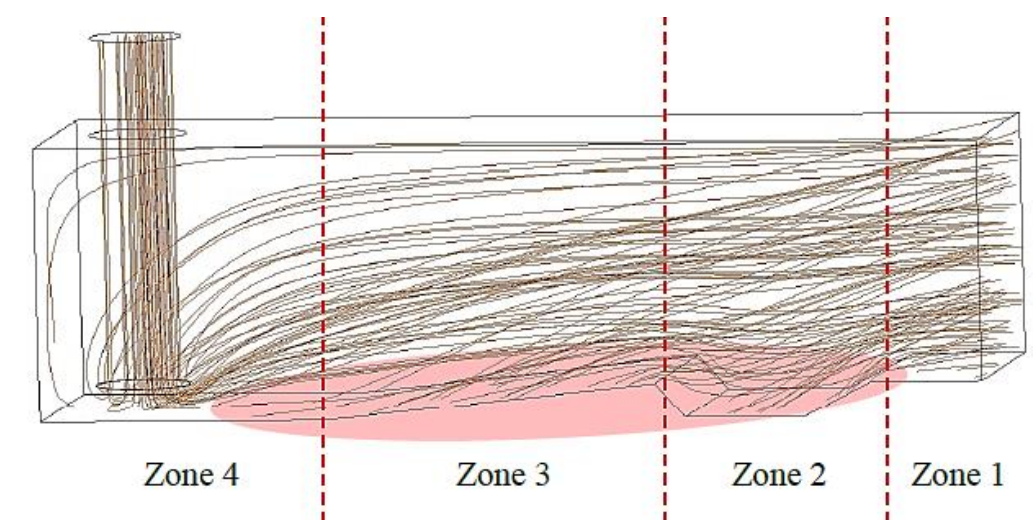

(a)

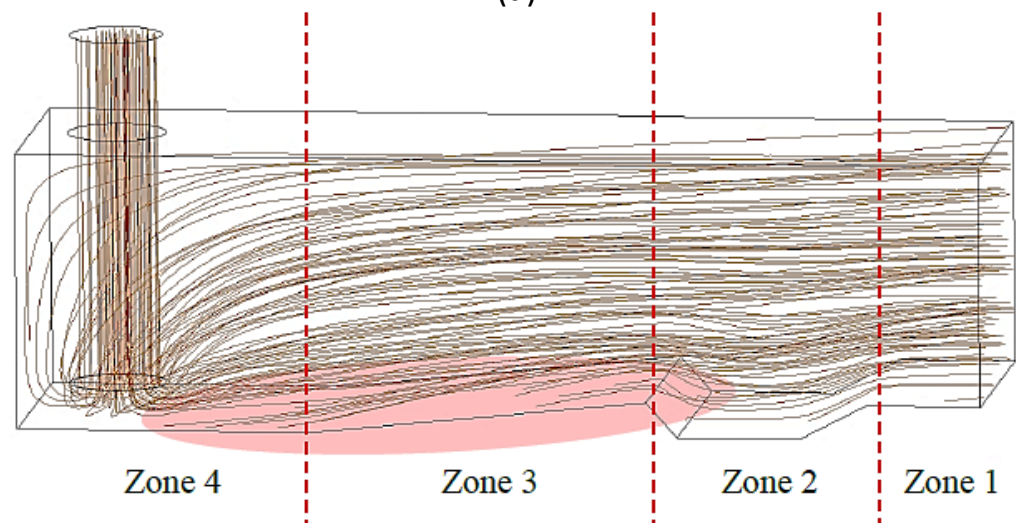

(b)

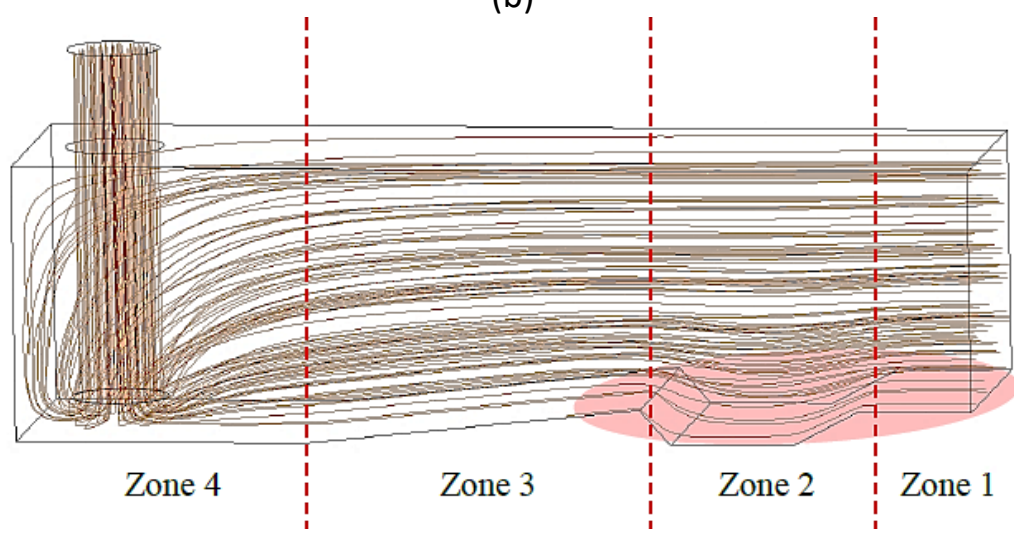

(c)

Fig. 5. (a)Velocity $0.037 \mathrm{~m} / \mathrm{s}$ with particle size $800 \mu \mathrm{m}$. (b) Velocity $0.037 \mathrm{~m} / \mathrm{s}$ with particle size $425 \mu \mathrm{m}$. (c) Velocity $0.037 \mathrm{~m} / \mathrm{s}$ with particle size $150 \mu \mathrm{m}$

\subsubsection{Case $3-$ Velocity $0.071 \mathrm{~m} / \mathrm{s}$ with difference particle sizes}

In this case, higher velocity is used which is $0.071 \mathrm{~m} / \mathrm{s}$. The particle deposited in the pump sump decreased more compared to Case 1 and 2. The deposition area for particle size $800 \mu \mathrm{m}$ has moved forward to Zone 2, 3 and 4. For particle size $425 \mu \mathrm{m}$, there are a few particles deposited at Zone 2, 3 and 4. Besides, for smallest particle size $150 \mu \mathrm{m}$, particle deposited at Zone 3 but in a small amount. 


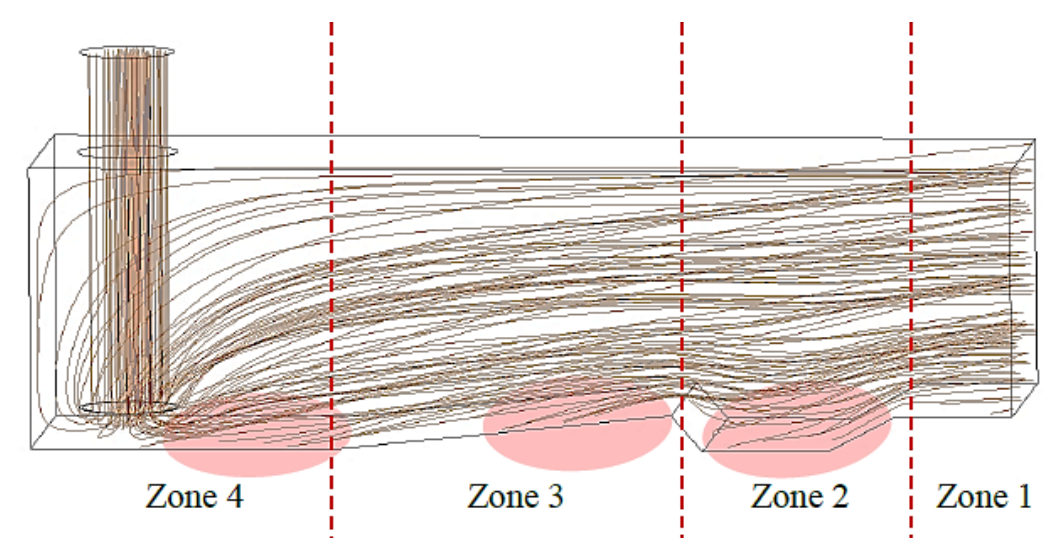

(a)

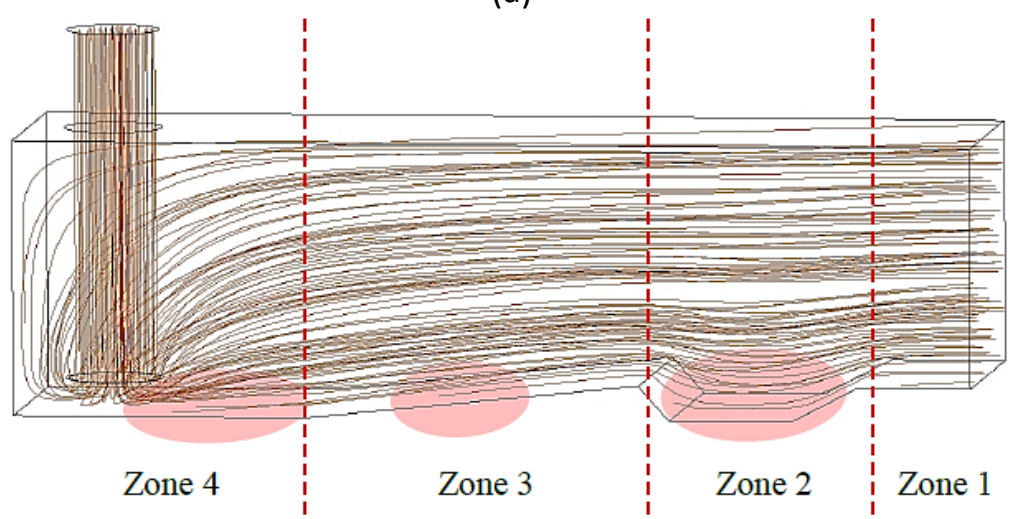

(b)

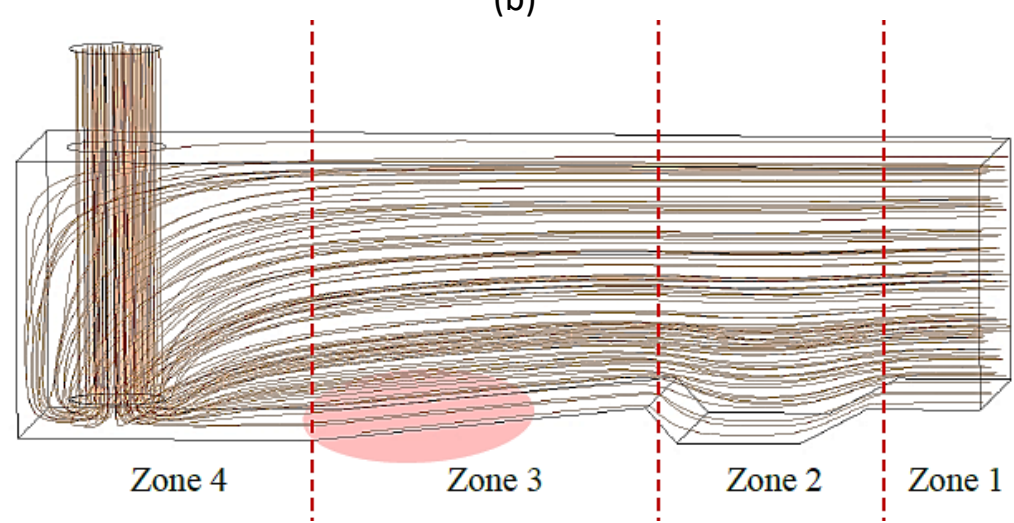

(c)

Fig. 6. (a) Velocity $0.071 \mathrm{~m} / \mathrm{s}$ with particle size $800 \mu \mathrm{m}$. (b) Velocity $0.071 \mathrm{~m} / \mathrm{s}$ with particle size $425 \mu \mathrm{m}$. (c) Velocity $0.071 \mathrm{~m} / \mathrm{s}$ with particle size $150 \mu \mathrm{m}$

The deposition area for minimum water level is the same as normal water level where when the velocity is slower, the deposition area of the sediment is located at the Zone 1 and 2 but more at the Zone 1 especially for particle size $800 \mu \mathrm{m}$. For the smallest particle size which is $150 \mu \mathrm{m}$, the particle deposited is more and dispersed compared to normal water level. Besides, as can be seen, the minimum water level has lower particle transported into the suction pipe. This is because of the lower water depth, the water velocity also decreased [19]. Therefore, the particle is easier to deposit in the pump sump. 


\subsection{Sediment Accumulation}

Sediment accumulation is interpreted in percentage in Figure 7 for normal water level and Figure 8 for minimum water level. For normal water level, particle size $800 \mu \mathrm{m}$ shows a higher percentage of particle accumulated in the pump sump especially in the velocity of $0.007 \mathrm{~m} / \mathrm{s}$ where the value is $76 \%$. When particle size $425 \mu \mathrm{m}$ is injected into the pump sump, it only gives slightly less percentage than $800 \mu \mathrm{m}$ at slowest velocity $0.007 \mathrm{~m} / \mathrm{s}$. When higher velocity applied which is $0.037 \mathrm{~m} / \mathrm{s}$, the particle accumulated in pump sump reduces from $61 \%$ to $23 \%$. While for the smallest particle size of $150 \mu \mathrm{m}$, there is a huge difference amount of percentage of particle accumulated in pump sump compared to other particle sizes where there is only $18 \%$ particle trapped in pump sump for velocity $0.007 \mathrm{~m} / \mathrm{s}$. Even in the slowest velocity, the amount of particle that accumulated is very small.

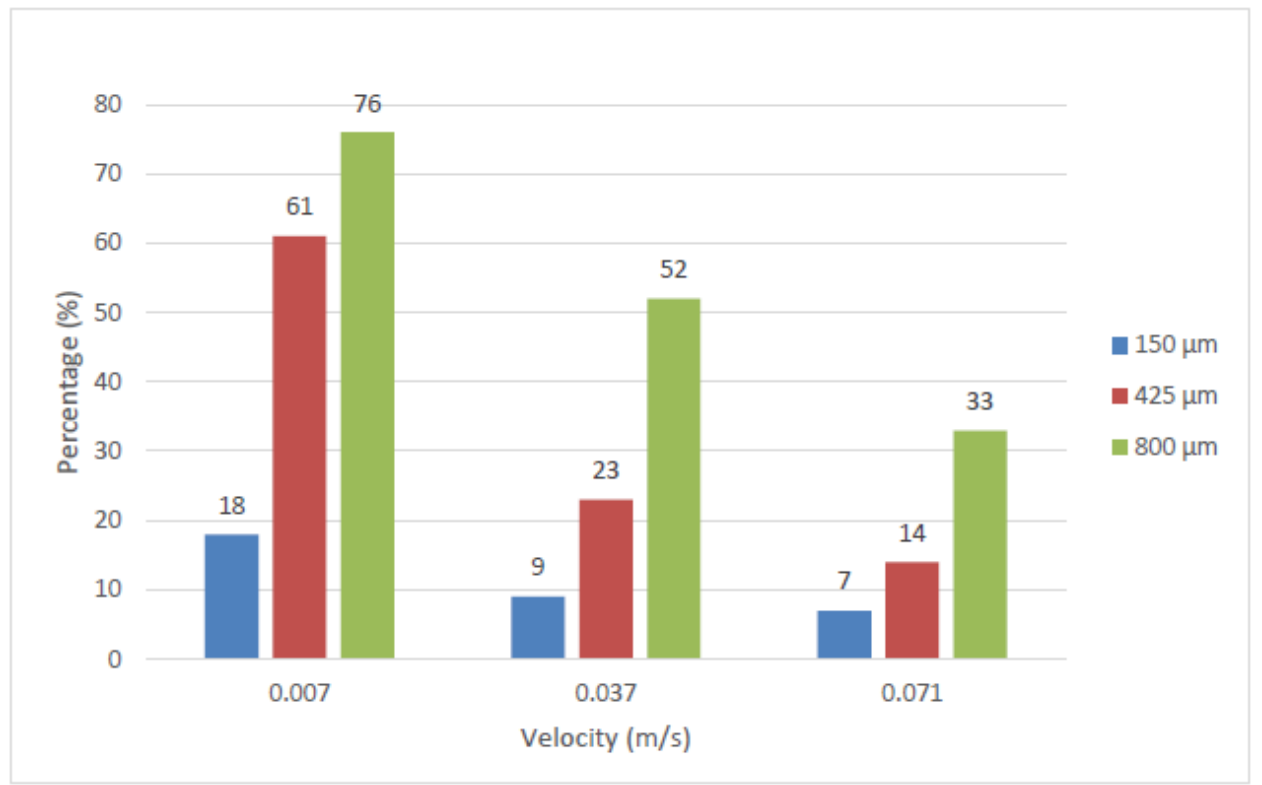

Fig. 7. Percentage of sediment accumulation for normal water level

Contrast to minimum water level, the percentage of particle accumulate is higher especially for $800 \mu \mathrm{m}$ and $425 \mu \mathrm{m}$. At velocity $0.007 \mathrm{~m} / \mathrm{s}$, percentage of particle trapped for particle size of $800 \mu \mathrm{m}$, $425 \mu \mathrm{m}$ and $150 \mu \mathrm{m}$ is $90 \%, 87 \%$ and $72 \%$ respectively. For particle size $800 \mu \mathrm{m}$, there are only $5 \%$ difference for all velocity which is $90 \%$ for $0.007 \mathrm{~m} / \mathrm{s}, 85 \%$ for $0.037 \mathrm{~m} / \mathrm{s}$ and $80 \%$ for $0.071 \mathrm{~m} / \mathrm{s}$. Besides, for particle size $425 \mu \mathrm{m}$, there are $87 \%, 76 \%$ and $67 \%$ of particle accumulated for velocity $0.007 \mathrm{~m} / \mathrm{s}, 0.037 \mathrm{~m} / \mathrm{s}$ and $0.071 \mathrm{~m} / \mathrm{s}$ respectively. Hence, there are only $11 \%$ and $9 \%$ differences. In addition, for smallest particle injected in pump sump which is $150 \mu \mathrm{m}$, the percentage drop $33 \%$ from $72 \%$ to $39 \%$ for $0.007 \mathrm{~m} / \mathrm{s}$ and $0.037 \mathrm{~m} / \mathrm{s}$. This shows that different water level, flow and sediment size influence the sediment accumulation in pump sump. [20] 


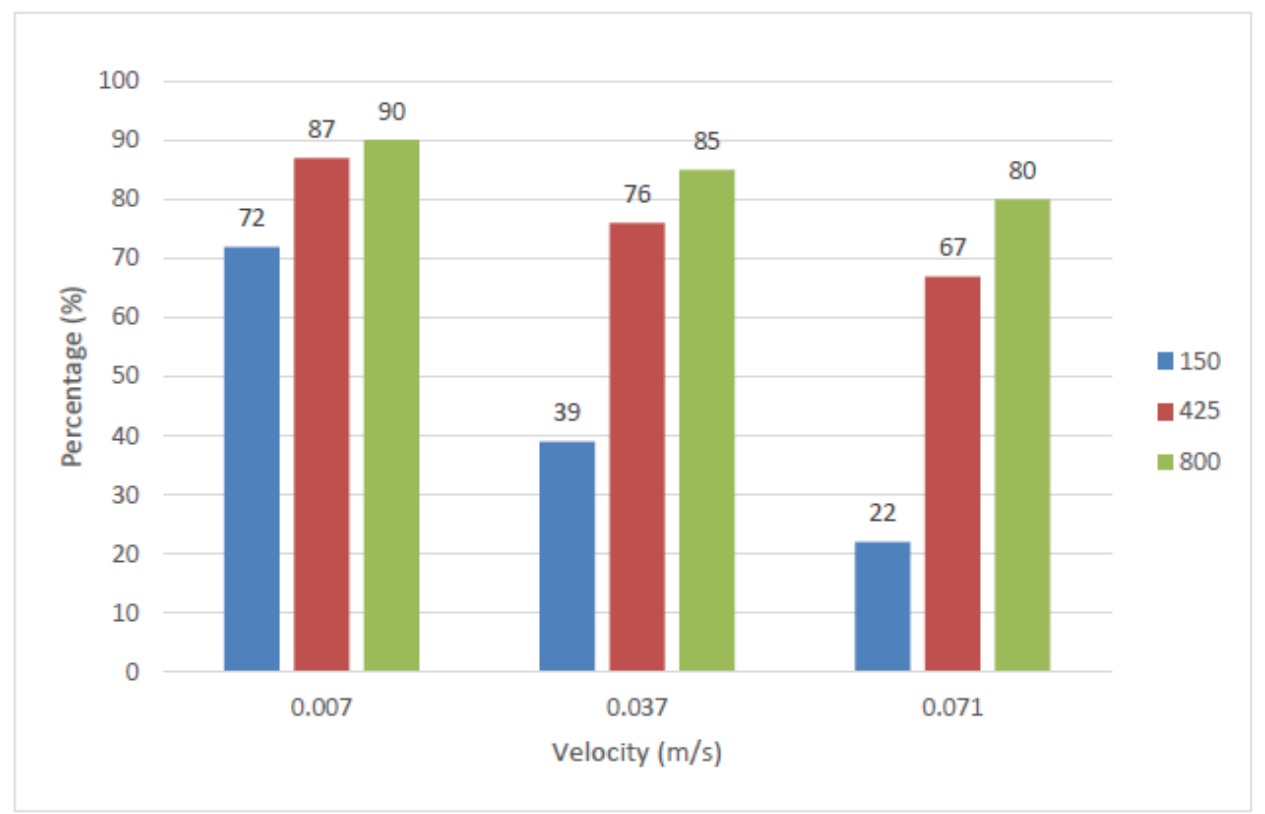

Fig. 8. Percentage of sediment accumulation for minimum water level

\section{Conclusions}

From the study, the percentage of particle accumulated in pump sump is decreased with increased velocity. Besides, the particle sizes also influence the particle deposition in pump sump. The bigger size of the particle gives a higher percentage of particle deposited in pump sump. The smaller particle size which is $150 \mu \mathrm{m}$ shows a higher percentage of particle transported to the suction pipe. This may lead to the sediment erosion to the pump sump or pump blade [21]. Besides, larger particle size gives a higher percentage of particle deposited especially in lower velocity and the deposited area located near to the inlet and slope section of pump sump. A higher number of particles deposited will cause a shortage of capacity in the reservoir [22]. Furthermore, the height of the water level also affected the percentage of particle transported into the suction pipe. Percentage of particle deposited in pump sump decreased with an increase in water level in pump sump.

\section{Acknowledgement}

The authors would like to thank Research Management Centre (RMC), Universiti Tun Hussein Onn Malaysia for funding this project under Postgraduate Research Grant (GPPS) vot no. H604.

\section{References}

[1] Bhardwaj, Vipin, and Bethany Reed. "Pumps." Water Encyclopedia 1 (2005): 391-395. https://doi.org/10.1002/047147844X.mw1825

[2] DID. “Urban Stormwater Management Manual for Malaysia." Department of Irrigation and Drainage. Percetakan Nasional Berhad. (2001)

[3] Gregory, John. Particles in water: properties and processes. CRC Press, 2005. https://doi.org/10.1201/9780203508459

[4] Hillebrand, G., I. Klassen, and N. R. B. Olsen. "3D CFD modelling of velocities and sediment transport in the Iffezheim hydropower reservoir." Hydrology Research 48, no. 1 (2016): 147-159. https://doi.org/10.2166/nh.2016.197

[5] Faghihirad, Shervin, Binliang Lin, and Roger Alexander Falconer. "Application of a 3D layer integrated numerical model of flow and sediment transport processes to a reservoir." Water 7, no. 10 (2015): 5239-5257.

https://doi.org/10.3390/w7105239 
[6] Shahidan, Noor FN, Zorkeflee A. Hasan, Mohd Z. Abdullah, and Aminuddin A. Ghani. "Mathematical modelling of flow and sediment pattern at ljok Intake, ljok River, Perak, Malaysia." International Journal of Modelling and Simulation 32, no. 3 (2012): 165-170.

https://doi.org/10.2316/Journal.205.2012.3.205-5595

[7] Samsudin, M. L., K. M. Munisamy, and Savithry K. Thangaraju. "Application of multiphase modelling for vortex occurrence in vertical pump intake-a review." In IOP Conference Series: Materials Science and Engineering, vol. 88, no. 1, p. 012024. IOP Publishing, 2015.

https://doi.org/10.1088/1757-899X/88/1/012024

[8] Andersson, Bengt, Ronnie Andersson, Love Håkansson, Mikael Mortensen, Rahman Sudiyo, and Berend Van Wachem. Computational fluid dynamics for engineers. Cambridge University Press, 2011.

https://doi.org/10.1017/CBO9781139093590

[9] Wingstedt, Emma M. M., and Reif, Bjørn Anders Pettersson. Numerical simulations of particle dispersion in an urban area. Norwegian: Norwegian Defence Research Establishment (FFI) Report, June 2012.

[10] Kaushal, D. R., T. Thinglas, Yuji Tomita, Shigeru Kuchii, and Hiroshi Tsukamoto. "CFD modeling for pipeline flow of fine particles at high concentration." International Journal of Multiphase Flow 43 (2012): 85-100. https://doi.org/10.1016/j.ijmultiphaseflow.2012.03.005

[11] Yan, Hexiang. "Experiments and 3D modelling of hydrodynamics, sediment transport, settling and resuspension under unsteady conditions in an urban stormwater detention basin." PhD diss., 2013.

[12] Gopaliya, Manoj Kumar, and D. R. Kaushal. "Modeling of sand-water slurry flow through horizontal pipe using CFD." Journal of Hydrology and Hydromechanics 64, no. 3 (2016): 261-272. https://doi.org/10.1515/johh-2016-0027

[13] Tarpagkou, Roza, and Asterios Pantokratoras. "CFD methodology for sedimentation tanks: The effect of secondary phase on fluid phase using DPM coupled calculations." Applied Mathematical Modelling 37, no. 5 (2013): 34783494.

https://doi.org/10.1016/i.apm.2012.08.011

[14] Bikmukhametov, Timur. "CFD Simulations of multiphase flows with particles." Master's thesis, NTNU, 2016.

[15] Dufresne, Matthieu, José Vazquez, Abdelali Terfous, Abdellah Ghenaim, and Jean-Bernard Poulet. "Experimental investigation and CFD modelling of flow, sedimentation, and solids separation in a combined sewer detention tank." Computers \& Fluids 38, no. 5 (2009): 1042-1049.

https://doi.org/10.1016/i.compfluid.2008.01.011

[16] Mohsin, Mohammad, and Deo Raj Kaushal. "3D CFD validation of invert trap efficiency for sewer solid management using VOF model." Water Science and Engineering 9, no. 2 (2016): 106-114. https://doi.org/10.1016/i.wse.2016.06.006

[17] Fluent, A. N. S. Y. S. "ANSYS fluent theory guide 15.0." Inc, Canonsburg, PA (2013).

[18] Saqr, Khalid M., Hossam S. Aly, Malzan A. Wahid, and Mohsin M. Sies. "Numerical simulation of confined vortex flow using a modified k-epsilon turbulence model." CFD letters 1, no. 2 (2010): 87-94.

[19] Dorfmann, D. I. C. "Flow Phenomena in a Reservoir investigated by Field Measurements and Numerical Modelling." PhD diss., PhD Thesis, Graz University of Technology, Austria, 2017.

[20] Tahir, N. M., Siti Hidayah Abu Talib, Muhammad Salleh Abustan, Syarifah Intan Najla Syed Hashim, and Radzaly NF I. "The effect of sediment sizes to pump sump system in physical modeling." In AIP Conference Proceedings, vol. 2129, no. 1, p. 020082. AIP Publishing LLC, 2019.

https://doi.org/10.1063/1.5118090

[21] Thapa, Biraj Singh, Ole Gunnar Dahlhaug, and Bhola Thapa. "Sediment erosion in hydro turbines and its effect on the flow around guide vanes of Francis turbine." Renewable and Sustainable Energy Reviews 49 (2015): 1100-1113. https://doi.org/10.1016/i.rser.2015.04.178

[22] Teh, Soo Huey. "Soil erosion modeling using RUSLE and GIS on Cameron highlands, Malaysia for hydropower development." PhD diss., 2011. 